\title{
Homem dos Lobos: A Atualidade dos Casos Clínicos Freudianos
}

The Clinical Story Of The Wolfman And Its Actuality

La Historia Del Hombre De Los Lobos Y Su Actualidad

Pontifícia

Universidade

Católica do

Rio de Janeiro

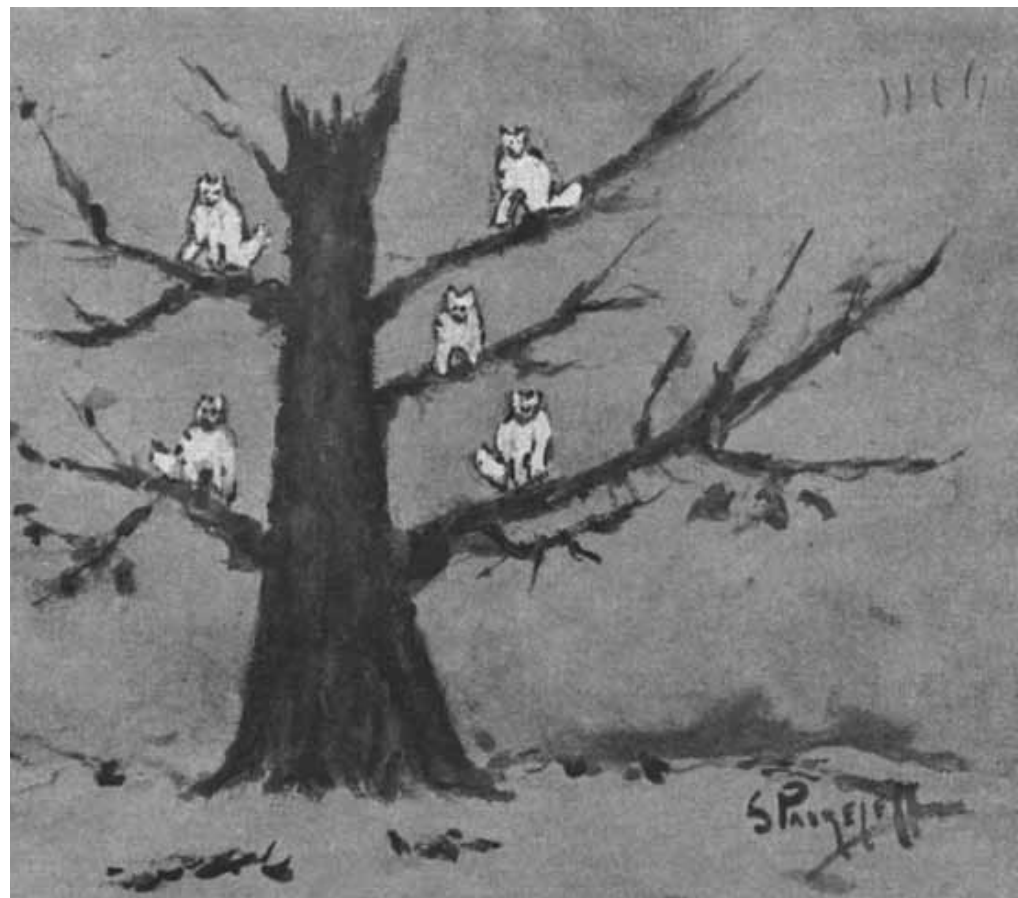


Resumo: Em que interessa hoje para o psicólogo clínico ou o psicanalista a leitura dos relatos clínicos de Freud? Para além de uma leitura obrigatória que deve constar em suas estantes, é preciso que algo que suscite sua prática esteja em jogo. Freud situa em seus relatos o que primeiramente é conceituado por Lacan como sujeito, puro furo, ponto onde culminam as linhas mestras de uma vida, o qual delimitaria o ponto extremo de singularidade. Posteriormente, Lacan propõe a delimitação desse furo como objeto, nomeia-o objeto a e propõe que essa extração seja o resultado da operação analítica. Trata-se de situar o modo como o caso do Homem dos Lobos pode auxiliar no entendimento dessas difíceis proposições.

Palavras-chave: Psicanálise. Freud, Sigmundo, 1856-1939. Teoria psicanalítica. Objeto. Caso clínico.

Abstrac: What good is it today, for a psychoanalyst, the readings of Freud's clinical accounts? Besides being an obligatory reading that must be in his/her library, it is necessary something that stimulates its practice. Freud places in his accounts what primarily is conceived by Lacan as the point in which the master lines of a lifetime culminate, which would mark the point that would fix the singularity of a subject. Afterwards, Lacan proposes the extraction of a paradoxical object in the course of an analysis, something he names object a. The work investigates how the case of the Wolf Man can give us the access to this element without objectifying it, but in conformity with the specificity that characterizes it.

Keywords: Psychoanalysis. Freud, Sigmundo, 1856-1939. Psychoanalytic theory. Object. Clinical case.

Resumen: ¿En qué interesa hoy al psicólogo clínico o al psicoanalista la lectura de los relatos clínicos de Freud? Para más allá de una lectura obligatoria que debe constar en sus estantes, es preciso que algo que suscite su práctica esté en juego. Freud sitúa en sus relatos lo que primeramente es conceptuado por Lacan como sujeto, agujero, punto donde culminan las líneas maestras de una vida, el cual delimitaría el punto extremo de singularidad. Posteriormente, Lacan propone la delimitación de este agujero como objeto, lo nombra objeto a y propone esta extracción como el resultado de la operación analítica. Se trata de situar el modo por el que el caso del Hombre de los Lobos puede auxiliar en el entendimiento de estas difíciles proposiciones.

Palabras clave: Psicoanálisis. Freud, Sigmundo, 1856-1939. Teoria psicanalítica. Objeto.Caso clínico.

\section{O Homem dos Lobos: a atualidade dos casos clínicos freudianos ${ }^{1}$}

Por que ler, hoje, o Homem dos Lobos? Qual seria o sentido - para o psicólogo, ou mesmo para o analista, às voltas com as tão concretas demandas do campo da saúde mental, das instituições carcerais, jurídicas, universitárias e tantas outras - dessa leitura? Ainda encerraria ela alguma orientação clínica válida?

\section{Versões do lobisomem}

A História de uma Neurose Infantil (1987 [1893-95]) pertence à galeria dos casos com que Freud instituiu os marcos fundamentais da clínica psicanalítica. O relato do tratamento de Serguei Pankejeff, cuja identidade só se tornou conhecida após sua morte, em 1979, foi decisivo na formação de várias gerações de analistas. Para todos os que ali puderam apreender algo da psicanálise, Serguei, no entanto, foi conhecido unicamente através do epíteto que Ihe deu Freud, o de Homem dos Lobos.

Dessa forma, apesar de referido a alguém de carne e osso, o caso foi sempre, essencialmente, um texto. Como tal, prestase a inúmeras leituras.

Pode, primeiramente, ser tomado como um clássico da literatura universal, patrimônio da humanidade. Ora, clássico poderia ser entendido como o que se presta à classe, bom para a sala de aula. Os clássicos são as obras classificadas, postas na gaveta ou no balcão de venda, que compõem o acervo de citações de um homem culto.

Se assim fosse, afora a deferência para com seu mais ilustre precursor, o psicanalista teria poucos motivos para debruçar-se sobre o Homem dos Lobos. Um caso só 
É uma forma tentadora de

lidar com os casos de Freud,

basta tomar seus

protagonistas

como

personagens.

O próprio Freud

reconhecia

que seus relatos

se liam como

romances, e

não faltaram

filmes que

tomaram os

pacientes de

Freud como

seres de ficção

(Freud, 1987

[1893-1895], p.

22). será clínico se seu valor de apreensão da atuação psicanalítica se mantiver preservada a cada novo leitor. Nesse sentido, que seja o Homem dos Lobos um clássico, mas em sintonia com as definições de Calvino, ou, mais informalmente, com a de Millôr Fernandes, para quem um clássico é "alguém que não se contentou em chatear apenas seus contemporâneos" (Calvino, 1993; Millôr, 1994; Miller, 2003).

Bom clássico é o que se mantém vivo em seus efeitos sobre leitores de várias gerações como texto-que-perturba. Isso talvez nos dê uma ideia mais aproximada do efeito causado pela convivência com Pankejeff à época em que entra em contato com Freud: ex-nobre, subserviente, esnobe, virulento e hipocondríaco, racional e enlouquecido.

Millôr não deixa de destacar, assim, o valor clínico da literatura, ou ao menos da boa literatura. Ela, tal como a psicanálise, verifica o poder da palavra sobre o corpo. Ainda estamos, porém, distantes da psicanálise, apesar de esse ser um dos modos de enquadramento insistentemente oferecidos a ela nos Estados Unidos, por exemplo, onde a encontramos nos departamentos de Letras e Literatura, ou mesmo de Filosofia, mas cada vez menos nos de Psicologia clínica.

É uma forma tentadora de lidar com os casos de Freud, basta tomar seus protagonistas como personagens. O próprio Freud reconhecia que seus relatos se liam como romances, e não faltaram filmes que tomaram os pacientes de Freud como seres de ficção (Freud, 1987 [1893-1895], p. 22). O Homem dos Lobos poderia, inclusive, ser lido sob o ângulo de uma epopeia iniciática em que, tal como o Sidarta, de Herman Hesse (2011), ou o Alquimista, de Paulo Coelho, atravessaríamos, com o protagonista, uma edificante ascese rumo à elevação terapêutico-espiritual.

O uso clínico da literatura distingue-se, no entanto, de um relato clínico. O relato, por parte do analista, de um tratamento, não visa a provocar, por si mesmo, o efeito obtido com o paciente, mas sim, a demonstração do modo como se operou para obtê-lo. No primeiro, os efeitos, eventualmente concretos, da leitura, serão considerados a partir de um plano dual entre autor e leitor. No segundo, algo do personagem em questão, irredutível à identificação do leitor com seu herói-personagem, deve necessariamente ser levado em conta.

Talvez isso explique porque nós, psicanalistas, costumamos valorizar dados da história do paciente. Buscamos compensar o efeito ficcional de nossos casos clínicos com o maior número possível de elementos, se não objetivos, ao menos concretos. Tentamos dar corpo ao homem através de sua história, trazer seu contexto para lhe dar um lugar no real.

\section{Da história ao homem}

O Homem dos Lobos é um prato cheio para os adeptos da História. Não morreu cedo como Ernst, o Homem dos Ratos, não resistiu a ter seu nome associado à psicanálise, como Bertha, a Anna O., nem esqueceu seu tratamento, como Max Graff, o pequeno Hans. Colocou-se à disposição da psicanálise e de seus historiadores, deu entrevistas, redigiu suas memórias. Viveu 92 anos e atravessou o século XX a ponto de sua história se confundir não somente com a da psicanálise, mas também com a do próprio século.

Exatamente por isso, o Homem dos Lobos é o que melhor nos ensina o erro da aposta na História como modo de dar lastro clínico ao caso. O livro de Muriel Gardiner, por exemplo, empenha-se em tornar público quem realmente teria sido Serguei Pankejeff (Gardiner, 1981). A autora reúne, ao texto de Freud, os relatos de tratamento de seus dois 
outros analistas, assim como as lembranças de Serguei sobre sua vida - incluindo as referentes a seu tratamento com Freud -além de um relato de seus últimos anos. Muito se pode, ali, aprender sobre o Homem dos Lobos ao modo de uma biografia a mais completa possível. Pouco se acrescenta, contudo, ao que o texto de Freud pode nos ensinar sobre a psicanálise.

Aprende-se, por exemplo, que Serguei foi tomado por um delírio claramente configurado no sentido psiquiátrico do termo em seu segundo tratamento, com Ruth Mack Brunswick. Nada nos permite concluir, porém, sobre o papel exato da psicanálise nesse quadro: ela havia protegido Serguei do delírio até então ou, ao contrário, o deflagrou? Acrescentar dados ao dossiê do personagem histórico não elimina a necessidade de uma operação de leitura que extraia da biografia um homem. Um personagem unicamente histórico terá sua verdade sempre refém do último revisionista que, de posse de novos dados, queira mudar o sentido do que terá sido. Mantendo-nos nesse plano, apenas por transferência para com o autor admitiríamos a interpretação de Freud como mais próxima do real que outras.

É nesse sentido que se encaminha a leitura do historiador Carlo Ginzburg, um dos grandes nomes da micro-História, ou História dos anais. Após estabelecer toda uma série de analogias entre o caso do Homem dos Lobos e elementos do folclore eslavo, documentos de um inquérito do século XVII sobre um lobisomem e a seita dos Andarilhos do Bem, de Friul, nos séculos XVI a XVIII, Ginzburg situa o sonho fundamental do caso como induzido por seu contexto cultural. Serguei, nascido com uma coifa e no dia do Natal, era de uma família aristocrática eslava, tinha sido criado por uma governanta inglesa e por uma nania eslava. As lendas eslavas vinculariam as pessoas que nascem com a coifa no Natal a poderes excepcionais, entre os quais o de se tornar lobisomem. A partir dessa série de indícios históricos, a neurose de Serguei se explicaria pelo fruto do conflito cultural ao qual estava submetido, entre a aristocracia e a cultura popular; de acordo com Ginzburg, "o homem dos lobos não seguiu o caminho que estaria aberto dois ou três séculos atrás. Em vez de se tornar lobisomem, tornou-se neurótico, à beira da psicose" (1991, p. 210).

Fica claro, portanto, que um caso psicanalítico deverá realizar a proeza de incluir seu real no próprio texto, sob pena de não se distinguir de uma ficção histórico-biográfica.

\section{Homus patologicus}

Antes, porém, de buscar delimitar esse tour de force, é preciso descrever um perigoso modo de contornar o relativismo que o ponto de vista contextual-histórico introduz. Trata-se de tomar o real como diretamente acessível, como entidade a-histórica que determinaria o leque de narrativas. O modo mais comum de incorrer nesse realismo ingênuo é definir o homem a partir de uma patologia. O Homem dos Lobos teria sido um psicótico, e não um neurótico obsessivo. Segundo Webster, Anna O. era, na verdade, uma epilética, mal diagnosticada por Breuer e Freud, e assim por diante (1995, pp. 105-132).

Essa patologização do real pode fornecer um lastro sólido à clínica face ao relativismo historicista, mas corre o risco de apenas conferir uma falsa impressão de domínio por simplesmente apor um sentido ao real. De fato, quando desestribada do trabalho clínico, da intervenção e da interação direta com o paciente, torna-se o que J. A. Miller e J. C. Milner designam máquina de impostura (Miller \& Milner, 2006). Apoiando-se em uma pseudomatematização do mundo psíquico, essa impostura se torna o mais bem acabado 
3 Agradeço a Elisa Werlang em Couto, M. E. Em torno do objeto da psicanálise, dissertação de mestrado, PUC-Rio, 2005, da qual retiro o essencial do que desenvolvo nessa passagem.

4 Agradeço a Tatiane Grova pelo achado.

É o que conduz

Lacan a dizer "a ação da fórmula que em todos os pontos submete o elemento massa à atração dos outros", referindose às orbes no lugar dos corpos (Lacan, 2003, pp. 420-429).

5 "O que nos faz dizer imediatamente (...) que a alquimia, afinal, não é uma ciência? Alguma coisa, a meus olhos, é decisiva, que a pureza da alma do operador era, como tal, e de modo determinado, um elemento essencial no negócio" (Lacan, 1985, p.16) fruto de nosso tempo obscurantista, em que o simples uso de números parece garantir a cientificidade do processo e assegurar proteção contra qualquer reflexão crítica.

Tomemos um exemplo, retirado da revista ÉPOCA. A inglesa Clio Cresswell, professora de Matemática na Austrália, em seu livro Mathematics and Sex, que está na lista dos mais vendidos nos Estados Unidos, destaca o modo como os psicólogos lidam com os padrões de comportamento comuns entre amantes: "criamos equações a partir desses padrões para conseguir prever o comportamento, otimizando os resultados. (...) Por exemplo: a seguinte equação surge a partir de um sistema que mede e dá notas às interações positivas e negativas registradas durante a conversa de um casal, filmada em vídeo. A variável I é o somatório dos fatores de persuasão de um membro do casal sobre o outro (do tom de voz conciliatório a um decote mais ousado) analisados e registrados pelos cientistas $(\ldots)$; apenas a título de curiosidade: $\mathbf{W t}+\mathbf{1}=\mathbf{a}+\mathbf{r} \mathbf{1 W} \mathbf{1}+\mathbf{I H W}(\mathbf{H} \mathbf{1})$ (Veiga \& Castro, 2005). ${ }^{3}$

\section{Galileu e Freud}

Estamos bem distantes da ciência, ao menos tal como situada pela leitura, por Lacan, de Alexandre Koyré. Nem o amor, nem o Homem dos Lobos poderiam ser objetivados pela ciência simplesmente porque, para ela, não existem seres externos à sua operação, a serem definidos a partir de equações. Ela não é o recobrimento do mundo pela Matemática, sua colonização pelas fórmulas. Trata-se, na verdade, de "substituir o mundo real da experiência quotidiana por um mundo geométrico hipostasiado" (Koyré, 1991, p. 184). ${ }^{4}$ Em vez de recobrimento, substituição. A ciência não traduz os seres em fórmulas, mas aborda-os como se fossem feitos de fórmulas. Em certo sentido, eles deixam de existir como seres, unidades prévias, e passam a ser tomados apenas como entes digitais, em um plano essencialmente literal-simbólico (Lacan, 2003, pp. 311-315).

A ciência considera que o universo do vivido seja regido por leis matemáticas e busca destacá-las, o que é o oposto de buscar produzir mera quantificação da experiência. A própria ideia de medir supõe um protocolo para que se crie a medição. "Com efeito, se uma experiência científica (...) constitui uma pergunta formulada à natureza, é claro que a atividade cujo resultado é a formulação dessa pergunta é função da elaboração da linguagem na qual essa atividade se exprime" (Miller, 1987, p. 44; cf. tb. Koyré, 1991, pp. 168-272).

Para fazê-lo, a ciência esvazia, em um procedimento do qual a dúvida hiperbólica de Descartes é o paradigma, tudo o que, em um dado universo, corresponde ao singular, a tudo o que propriamente chamaríamos de temperamental ou, com Freud, estranho. Reduz-se o estranho a um ponto, que é em seguida descartado, ou foracluído, segundo Lacan. Nada mais poderá ser dito/escrito do que no Homem dos Lobos é seu elemento singular. É isso que recuperamos com o termo sujeito. ${ }^{5}$

Essa verdadeira "ideologia da supressão do sujeito", como Lacan define a ciência, é, no entanto, essencial à psicanálise. Esta traz a singularidade à tona não mais como um corpo de sentidos históricos, atávicos ou mágicos, mas como um ponto cego, exatamente aquele produzido pela ciência no mesmo movimento em que o descarta (Lacan, 2003, p. 436). É esse sujeito que permitirá à psicanálise constituir-se como prática original de lida com o real - ponto nevrálgico de uma existência - como vazio de sentido. Em vez de um Homem, situado pelos valores e sentidos da tradição, tal como 
Ginzburg (1991) visa a resgatar, em Freud, encontramos uma casa vazia, ponto de convergência dos determinantes estruturais de uma história que são retomados um a um por Freud e entrecruzados na complexa trama que constitui a história clínica de Serguei Pankejeff. Tudo converge para os lobos, e destes, para a construção da cena primitiva. Em uma lista aleatória e nada exaustiva, podemos citar: abrir os olhos, posição erguida do pai, abre-se a janela, olhar, posição anal erótica, ser olhado, lobo sem rabo, lobo erguido (angústia), te como, sexo como violência, órgãos sexuais dos pais, ser devorado, lobo sobre a árvore, os sete cabritinhos, lobo sob a árvore, lobos tranquilos, movimento violento, voyeurismo, mãe dos cabritinhos, imobilidade, árvore de natal, seis ou sete lobos, gozo na posição feminina, angústia de morte, angústia de castração, ovelhas mortas, investigações sexuais, malária, morte, cães pastores, febre às 5 da tarde, cinco lobos no deserto, $5 \mathrm{da}$ tarde, lobos brancos, cena aos quatro anos, tenra idade, verão, mulheres grandes com grandes nádegas, expressão de gozo da mãe, pais em roupas íntimas, um + meio ano de idade, barras do berço, pais em roupas íntimas, coitus a tergo.

Compreende-se porque a psicanálise, à diferença da ciência, não procede por um conhecimento cumulativo. Ela não prolongará as ramificações acima em direção a uma rede cada vez mais vasta de saberes sobre seus pacientes. Ela procederá, para cada caso, tal como Freud, a um delineamento da rede dos conhecimentos de uma vida apenas para chegar a seu umbigo, a seu ponto vital. Os conhecimentos sobre o Homem podem variar contextualmente e mesmo evoluir. Os conhecimentos sobre o que faz cada homem ser o que é, por outro lado, são necessariamente limitados a uma existência e deverão ser reconstituídos, caso a caso, de modo muito próximo ao trabalho realizado por Freud com o Homem dos Lobos.

\section{Sujeito e objeto: neurose e psicose}

Nota-se bem como a abordagem freudiana, já ensinava Lacan, é, em muitos aspectos, estrutural (2003, p. 429). Ela permite destacar, como se vê acima com precisão, o sujeito como casa vazia - encruzilhada dos sentidos, sem ser, essa casa, um sentido (Deleuze, 1979, p. 328). O Lobo não é um sentido histórico nem patológico para o real de Pankejeff, mas um nome de sujeito, pura abertura às significações de um modo de viver que não é, em si, tomada em um sentido específico. A cada passagem por esse ponto em uma análise, as versões que para ele convergem se recombinam, levando à redistribuição das cartas de uma história. Pode-se, assim compor um novo cenário, uma nova narrativa egoica, com mudanças subjetivas efetivas.

Essa concepção de tratamento, solidária com a noção de sujeito tal como o estruturalismo o concebe, não pode, porém, nos bastar; delimita uma terapia por demais pragmáticorelativista, em que descrições e redescrições são definidas de modo quase gratuito, e não nos fornece orientação quanto ao destino do tratamento ou a sua conclusão. Afinal, caso nos mantenhamos no plano das narrativas, qual seria mais apropriada que outra?

A única saída, já que o realismo ingênuo foi descartado, estaria em uma superação do plano das versões pela realização da essência do sujeito como pura abertura à existência. Nessa assunção da castração, ou realização da divisão subjetiva, modo como, em nosso meio, veiculamos às vezes essa quase ilusão, reside o melhor e o pior de uma concepção de tratamento limitada à noção de sujeito como localização ôntica de um dasein, cujas veias heideggerianas situam o analista como um asceta do autêntico, artífice supremo de sua própria divisão. 
Cabe, então, a pergunta: se o sujeito é essa variável presente nas lacunas de cada uma de suas versões, o que condicionaria o leque de versões? Se o sujeito é uma variável, qual a constante? Lacan responde: o objeto. Isso, se seguirmos J. A. Miller, que segue Lacan para destacar a regra fundamental da psicanálise, a associação livre, como autorização de um falar sem referência na realidade. Com base nisso é que se poderá delimitar o objeto peculiar da psicanálise. Uma análise tem início quando se suspende o critério clássico de verdade que supunha a adequação entre um dito e seu referente. Tudo, em uma análise, é narrado, e nada é questionado em seu valor de verdade com relação à sua adequação aos objetos do mundo. Ao se suspender a verificação do referente dos ditos ali enunciados, não se elimina, contudo, a dimensão real da referência. Ela é até mesmo amplificada. Ocorre apenas que o referente passa a ser essencialmente suposto; anunciase como aquilo que, em uma história, dá vida ao homem e lastro a suas narrativas não mais casa vazia, mas estranha presença (Miller, 1986/1987).

É exatamente o que será conceituado por Lacan como o objeto a que pode ser depreendido do trabalho de Freud com a construção da cena primitiva. ${ }^{6}$ Se há uma questão que o Homem dos Lobos permite localizar com precisão é a da articulação entre sujeito e objeto. De um lado, temos o lobo como nome de sujeito, de outro, o objeto, ou melhor, o sujeito tomado como objeto, na cena primordial, puro olhar assistindo ao coito parental.

Vieira, $M$.

A. (2008).

Restos - uma introdução lacaniana ao objeto da psicanálise,

Rio de Janeiro:

Contra Capa.

7 Cf. Lacan, J. Escritos, Rio de Janeiro, JZE, 1998, p. 387.

Talvez possamos, com base nessa dicotomia evidentemente esquemática, propor uma partilha provisória: na neurose, a funçãosujeito prima; na psicose, por outro lado, é como objeto da linguagem, como presa da fala do Outro, que encontramos o falasser.

Na neurose, algo intervém entre a linguagem e o falante, entre o que é ouvido e o que será escutado. A esquize entre ouvido e escuta, ou ainda entre olhar e visão, como destaca Lacan em seu Seminário 11, se institui na neurose com a presença, entre esses dois polos, de um vazio enigmático, lugar do sujeito, ou da famosa caixa preta dos behavioristas. Esse ponto de interposição é mantido em seu lugar pela crença em algo mais, em um sentidoporvir, a ser obtido junto ao Pai (Lacan, 1985).

Na psicose, o que se ouve pode ir diretamente ao ouvido. É a alucinação, insuportável presença da linguagem fora do sentido, que toma o corpo sem a intermediação da significação fálica (que nada mais é do que a significação de que há um sentido maior para as coisas). Serguei fornece a Lacan o exemplo paradigmático da alucinação do dedo cortado como demonstração real da fala "vão te cortar o membro" de sua nania. Lacan nos permite vislumbrar, para além da montagem imaginária que acompanha a alucinação, sua força real de presença, do qual o delírio virá constituir um sentido, intermediando o encontro da linguagem com o vivente. ${ }^{7}$

Até certo momento do lacanismo, esse elemento interposto era tido, por excelência, como a significação fálica, solidária do Nome do Pai. Isso definia dois caminhos distintos: ou bem a significação fálica, ou a catástrofe subjetiva, a qual apenas uma compensação (conhecida como metáfora delirante) evitaria. Os analistas têm sido levados a reconhecer, porém, toda uma série de casos em que essa intermediação não parece nada dever ao Nome do Pai, sem deixar, no entanto, de se fazer presente, por vezes de modo bastante eficaz.
O campo freudiano, como comunidade analítica de trabalho, definiu, sob a batuta de J. A. Miller, para esses casos, a noção de psicose corriqueira ou psicose ordinária. Não se trata de um diagnóstico a mais para o real, que nos levaria de volta ao realismo 
ingênuo, agora complementado por uma astrologia judiciária lacaniana em que apenas quatro tipos (neurose, psicose, perversão e inclassificável) responderiam por todo o leque do real humano. A clínica lacaniana dos inclassificáveis não é a clínica dos bordeline. Ela é, sobretudo, um modo de colocar a necessidade de remanejar nossos conceitos para trabalhar com o Outro de nossos tempos (Gueguen, 2002).

\section{Sintoma e grupo}

Talvez possamos, então, estabelecer uma epistemologia provisória, algo clínica. Nossa prática só nos permite lançar em direção à cultura algumas ideias provisórias sobre a própria cultura, por ela ser o parceiro fundamental dos sujeitos que ouvimos. A psicanálise não encontra o real sob o signo do novo, mas sim, do antigo, do filogenético, da repetição, nos termos de Freud; daquilo que retorna sempre no mesmo lugar, nos termos de Lacan. Em vez de falarmos de novos sintomas ou de um novo real, estaremos mais em sintonia com nosso trabalho quotidiano se buscarmos delinear a conformação atual da cultura tal como ela incide nos relatos que ouvimos: um novo Outro em lugar de um novo real (Miller, 1998).

Nesse sentido, os casos de psicose ordinária, tal como poderíamos diagnosticar Pankejeff, ao exibir diferentes modos de lida com o real, distintos da premissa universal do falo, nos fornecem a possibilidade de interrogar o estatuto do Outro contemporâneo, essencialmente, do papel, nele, do Nome do Pai. Tomar o Homem dos Lobos a partir do conceito de psicose ordinária nos permite, em certa medida, lidar com ele tal como Freud o fez, como campo de exploração terapêutica dos limites do campo subjetivo e, ao mesmo tempo, do campo psicanalítico.

O sucesso da psicose ordinária, em nossos dias, é, em muitos aspectos, o fracasso da psicose extraordinária - da paranóia com seu cortejo de delírios megalomaníacos, místicos, etc. Ele narra a dificuldade atual de se construir grandes sistemas delirantes espelhando-se no edifício paterno, uma vez que o Pai já não mais sustenta as poderosas instituições verticais de outrora. $\mathrm{O}$ sucesso da psicose ordinária traduz também, dessa forma, o fracasso da neurose clássica, fundada na crença na exceção paterna como modo de conciliação ente desejo e gozo; traduz ainda o surgimento de uma neurose ordinária, mais afeita a depressões e pânicos e menos a um trabalho subjetivo ou dimensão fantasística evidente.

Desse ponto de vista, os sujeitos fracassam quando são incapazes de interpor uma distância eficaz entre o ouvido e o escutado. No caso da neurose, isso se faz habitualmente, de modo prêt-à-porter, pela função de um vazio enigmático de saber, cujo segredo é detido pelo Pai. No segundo, uma invenção singular será um trabalho incessantemente exigido ao sujeito. Para ambos, Lacan (2007) destacará o termo sinthoma, designando assim de modo original essa invenção. O sinthoma poderá ser encontrado por extração, a partir do enigma, como no caso da neurose, ou por construção, bricolagem, como no caso da psicose. Em ambos, ele é a marca de uma articulação contingente entre gozo e significante, e inscreve, nessa suprema contingência, a impossibilidade da relação sexual (Miller, 2000).

O Nome do Pai, agora apenas um caso particular de sinthoma, pode, então, como invenção em escala industrial (pois é apenas a fé compartilhada de que alguém em algum lugar sabe o sentido da vida), ser colocado em contraposição às soluções artesanais da psicose. A psicose ordinária referenda, assim, a tese de J. A. Miller, a partir do último ensino de Lacan, do sintoma generalizado. Ela destaca o quanto estamos em tempos de sintomas em 
lugar de sujeitos.

É preciso que estejamos nos lugares em que possamos verificar se é possível passar dos sintomas aos sujeitos, do universal de uma identificação sintomática ao singular de uma enunciação única sobre o sintoma de cada um. Essa aposta pode ser verificada tanto em consultórios quanto em hospitais e alhures. Nesses verdadeiros campos de testes para o fazer psicanalítico, Serguei Pankejeff pode manter seu lugar de professor de desidentificação, precursor dos extraídos do sistema de hoje, rebeldes aos programas e pesquisas controladas, resistentes à rede de cuidados e alheios à internet. Esperemos que o psicanalista continue com eles aprendendo a produzir um sintoma singular e a fazer valer o lugar dessa singularidade no Outro.

\section{Marcus André Vieira}

Doutor em Psicanálise pela Université de Paris VIII. Professor assistente da Pontifícia Universidade Católica do Rio de Janeiro, Rio de Janeiro - RJ - Brasil.

E-mail: mav@litura.com.br

\section{Endereço para envio de correspondência:}

Rua Almirante Salgado, 377, Laranjeiras, Rio de Janeiro - RJ - Brasil. CEP: 22240-170

Recebido 7/12/2010, 1a Reformulação 22/3/2012, Aprovado 24/5/2012. 


\section{Referências}

Calvino, I. (1993). Por que ler os clássicos? São Paulo: Cia. das Letras.

Deleuze, G. (1979). A quoi recconnaît-on le structuralisme? In F. Chatelêt (Org.), Histoire de la philosophie, (Vol. IV, pp. 299-335). Paris: Marabout.

Freud, S. (1987). "Estudos sobre a histeria" In Edição standard brasileira das obras psicológicas completas de Sigmund Freud (). Salomão, trad., 2a ed., Vol. II). Rio de Janeiro: Imago (Trabalho original publicado em 1893-1895).

Gardiner, M. (Org.). (1981). L.homme aux loups par ses psychanalystes et par lui-même. Paris: Gallimard.

Ginzburg, C. (1991). Chaves do mistério: Morelli, Freud e Scherlock Holmes. In U. Eco, O signo de três (pp. 90-129). São Paulo: Perspectiva.

Gueguen, P. G. (2002). La homestasie symptomatique dans les psychoses. La lettre mensuelle, 211. Paris: ECF.

Hesse, H. (2011). Sidarta, (20a ed.). São Paulo: Ed. Record.

Koyré, A. (1991). Estudos de história do pensamento científico. São Paulo: Forense Universitária.

Lacan, J. (1985). O Seminário, livro 11. Rio de Janeiro: JZE.

Lacan, J. (2000). O Seminário, livro 5. Rio de Janeiro: JZE.

Lacan, J. (2003). Outros escritos. Rio de Janeiro: JZE.

Lacan, J. (2007) O Seminário, livro 23. Rio de Janeiro: JZE.
Miller J. A., \& Milner J. C. (2006). Você quer mesmo ser avaliado? São Paulo: Manole.

Miller, J. A. (1987). Cause et consentement. A orientação lacaniana, lição de 15-05-87. (Trabalho original publicado em 1986)

Miller, J. A. (1987). Matemas. Rio de Janeiro: JZE.

Miller, J. A. (1987). Percurso de Lacan: uma introdução. Rio de Janeiro: JZE.

Miller, J. A. (1998). O sintoma e o cometa. In Fundação do Campo Freudiano, O sintoma charlatão (pp. 8-9). Rio de Janeiro: JZE.

Miller, J. A. (2000). Teoria do parceiro. In Escola Brasileira de Psicanálise, Os circuitos do desejo na vida e na análise (pp. 153-207). Rio de Janeiro: Contra Capa.

Miller, J. A. (2003). Prólogo. In J. Lacan, Outros escritos (pp. 11 13) Rio de Janeiro: JZE.

Millôr, F. (1994). A bíblia do caos. Porto Alegre: LPM.

Vários. (1999). La psychose ordinaire. Paris: Agalma/Seuil.

Veiga, A., \& Castro, I. (2004). A matemática do amor. Revista Época, 35, 2-10.

Webster, R. (1995). Porque Freud errou. Rio de Janeiro: Record. 